\title{
Structure-Function Analysis of Two Variants of Mumps Virus Hemagglutinin-Neuraminidase Protein
}

\author{
Gerardo Santos-López ${ }^{1}$, Thomas Scior ${ }^{2}$, María del Tránsito Borraz-Argüello ${ }^{1}$, Verónica Vallejo-Ruiz ${ }^{1}$, Irma Herrera-Camacho ${ }^{3}$, \\ José Tapia-Ramírez ${ }^{4}$ and Julio Reyes-Leyva ${ }^{1}$ \\ ${ }^{1}$ Laboratorio de Biología Molecular y Virología, Centro de Investigación Biomédica de Oriente, Instituto Mexicano del Seguro Social, Metepec, \\ Puebla, México; ${ }^{2}$ Departamento de Farmacia, Facultad de Ciencias Químicas; ${ }^{3}$ Centro de Química, Instituto de Ciencias, Benemérita \\ Universidad Autónoma de Puebla, Puebla, Pue., México; ${ }^{4}$ Departamento de Genética y Biología Molecular, Centro de Investigación y Estudios \\ Avanzados, Instituto Politécnico Nacional, México, D.F., México
}

\begin{abstract}
A point mutation from guanine $(G)$ to adenine $(A)$ at nucleotide position 1081 in the hemagglutinin-neuraminidase (HN) gene has been associated with neurovirulence of Urabe AM9 mumps virus vaccine. This mutation corresponds to a glutamic acid (E) to lysine $(\mathrm{K})$ change at position 335 in the HN glycoprotein. We have experimentally demonstrated that two variants of Urabe AM9 strain $\left(\mathrm{HN}-\mathrm{A}_{1081}\right.$ and $\left.H \mathrm{HN}-\mathrm{G}_{1081}\right)$ differ in neurotropism, sialic acidbinding affinity and neuraminidase activity. In the present study, we performed a structure-function analysis of that amino acid substitution; the structures of HN protein of both Urabe AM9 strain variants were predicted. Based on our analysis, the $\mathrm{E} / \mathrm{K}$ mutation changes the protein surface properties and to a lesser extent their conformations, which in turn reflects in activity changes. Our modeling results suggest that this $\mathbf{E} / \mathrm{K}$ interchange does not affect the structure of the sialic acid binding motif; however, the electrostatic surface differs drastically due to an exposed short alpha helix. Consequently, this mutation may affect the accessibility of HN to substrates and membrane receptors of the host cells. Our findings appear to explain the observed differences in neurotropism of these vaccine strains.
\end{abstract}

Key-Words: Hemagglutinin-neuraminidasa, mumps virus, paramyxovirus, 3D structure prediction, sialic acid.

Mumps virus $(\mathrm{MuV})$ is a negative-sense single-stranded RNA virus belonging to the Paramyxoviridae family; $\mathrm{MuV}$ causes an acute infectious disease with fever, headache, myalgia and parotitis in children and young people. Massive vaccination programs have decreased the incidence of $\mathrm{MuV}$ infection worldwide; however, mumps epidemics have reemerged and its incidence is rising in several countries [1-3].

Several MuV strains, including L-Zagreb, Leningrad-3 and Urabe AM9, have been associated with a high incidence of post-vaccinal aseptic meningitis [4-6]. The Urabe AM9 strain has several viral subpopulations that vary at different positions in their genomes. One polymorphic site that defines two viral subpopulations, possessing either guanine or adenine (G/A) at position 1081 in the hemagglutinin-neuraminidase $(\mathrm{HN})$ gene that codes for glutamate $(\mathrm{E})$ or lysine $(\mathrm{K})$ at position 335 of the $\mathrm{HN}$ protein, has been frequently associated with postvaccination meningitis cases [7]. The frequent isolation of viruses with the $\mathrm{HN}-\mathrm{A}_{1081}$ genotype in post-vaccination meningitis cases has led to extensive discussion concerning the usefulness of this mutation as a genetic marker for virulence [7-10]. However, the role played by this mutation in mumps virus virulence is not well understood.

Recently, we identified a virus variant isolated from Urabe AM9 vaccine with $\mathrm{HN}-\mathrm{K}_{335}$ that was efficiently replicated in both human neuroblastoma cells and newborn rat brain; under

Received on 16 July 2008; revised 5 December 2008.

Address for correspondence: Dr. Gerardo Santos-López. Laboratorio de Biología Molecular y Virología, Centro de Investigación Biomédica de Oriente, Instituto Mexicano del Seguro Social, Km. 4.5 Carretera Federal Atlixco-Metepec, 74360 Metepec, Puebla, México. Phone. (Fax): +52 2444440122; E-mail: gerardo.santos.lopez@gmail.com; gerardo.santos@imss.gob.mx.

The Brazilian Journal of Infectious Diseases

2009;13(1):24-34. (C) 2009 by The Brazilian Journal of Infectious Diseases and Contexto Publishing. All rights reserved. the same conditions $\mathrm{HN}-\mathrm{E}_{335}$ virus replicated very little [11]. The MuV HN glycoprotein recognizes sialylated glycoconjugates as receptors, leading to virus attachment to host cell membranes and entry into the cell. Due to its sialicacid binding activity, the $\mathrm{HN}$ glycoprotein is responsible for hemagglutination and hemadsorption. Viral HN glycoprotein is a specific sialic-acid-binding lectin (HA, hemagglutination) that recognizes glycoconjugate molecules as receptors for the virus to attach to membrane surfaces of host cells. HN also acts as an enzyme (NA, neuraminidase or sialidase) that removes sialic acid (neuraminic acid) moieties from viral progeny to prevent self-aggregation, favoring the release of virions from the cell. In addition, $\mathrm{HN}$ activates fusion protein, thereby participating in the internalization of viral particles through the fusion of the cell and viral membranes [12].

We have found that $\mathrm{HN}-\mathrm{K}_{335}$ virus possesses higher affinity towards $\alpha 2,6$-linked sialic acid residues than does the $\mathrm{HN}-\mathrm{E}_{335}$ virus. This type of sialic acid is abundantly exposed on the membrane surface of human neuroblastoma cells, facilitating $\mathrm{HN}-\mathrm{K}_{335}$ virus entry into the cells. Additionally, $\mathrm{HN}-\mathrm{K}_{335}$ virus has 11 times higher neuraminidase activity than does $\mathrm{HN}-\mathrm{E}_{335}$, contributing to virus release [13].

Our objective was to explore other functional differences between the viral variants and how the $\mathrm{E}_{335} / \mathrm{K}$ substitution affects the putative structure and other physicochemical properties of $\mathrm{MuV} \mathrm{HN}$ protein. The in silico-generated structures for $\mathrm{HN}-\mathrm{E}_{335}$ and $\mathrm{HN}-\mathrm{K}_{335}$ proteins were compared, and their putative impact on activity and function were examined.

\section{Material and Methods}

Viruses and Cells

The $\mathrm{HN}-\mathrm{K}_{335}$ and $\mathrm{HN}-\mathrm{E}_{335}$ variants of Urabe AM9 mumps virus vaccine were initially purified by plaque assay [11]. The 
viruses were replicated in green monkey kidney Vero and CV1P cells and human neuroblastoma SH-SY5Y cells grown in high glucose Dulbecco's modified minimum essential medium, supplemented with $10 \%$ fetal bovine serum, $100 \mathrm{U} / \mathrm{mL}$ penicillin and $100 \mu \mathrm{g} / \mathrm{mL}$ streptomycin. The medium was also supplemented with non-essential amino acids and $8 \mathrm{mM}$ sodium pyruvate for culturing SH-SY5Y cells. All media and culture supplements were purchased from Sigma-Aldrich Chemicals (St. Louis, MO, USA).

\section{Hemadsorption Assays}

The hemadsorption activity of $\mathrm{MuV}$ variants was determined in infected cell cultures at $4^{\circ} \mathrm{C}$. Monolayers of Vero cells at 48 hpi were washed with DMEM and incubated for $30 \mathrm{~min}$ with a $2 \%$ suspension of human $\mathrm{O} \mathrm{Rh}+$ erythrocytes in DMEM. After extensive washing, the erythrocytes adsorbed on membrane cells were observed and their numbers estimated visually with phase contrast microscopy.

\section{Trypsin Treatment of Susceptible Cells}

SH-SY5Y cells were cultured on 24-well plates. At $24 \mathrm{~h}$ after seeding, the cells were treated with different concentrations of bovine pancreatic trypsin for $10 \mathrm{~min}$ at $37^{\circ} \mathrm{C}$. Cells were then washed twice with DMEM and inoculated with virus. Untreated cells were also inoculated with either $\mathrm{HN}-\mathrm{K}_{335}$ or $\mathrm{HN}-\mathrm{E}_{335}$ viruses and used as controls. Viral titers in recovered supernatants were determined by counting plaqueforming units per $\mathrm{mL}(\mathrm{PFU} / \mathrm{mL})$ in $\mathrm{CV}-1 \mathrm{P}$ cells at $48 \mathrm{hpi}$, as described previously [11].

\section{Sialic Acid-Binding Affinity}

Affinity for sialic acid was tested in competitive antiviral assays, as reported previously [13]. Briefly, each virus variant was mixed with $5-200 \mu \mathrm{g} / \mathrm{mL}$ of colominic acid ( $\alpha 2,8$-linked polysialic acid) and incubated for $1 \mathrm{~h}$ at $4^{\circ} \mathrm{C}$. The same concentrations of lactose or D-galactose were used as a control of virus infection inhibition. Culture supernatants were collected at $48 \mathrm{~h}$ pi, and viral titers were calculated as $\mathrm{PFU} / \mathrm{mL}$ in CV-1P cells. Regression analyses of antiviral data were performed with KyPlot v2.0 beta 13 software (www.woundedmoon.org/win32/kyplot.htmL). Dose-response equations were used to calculate the $50 \%$ inhibitory concentration $\left(\mathrm{IC}_{50}\right)$ values for each oligosaccharide and virus variant.

Sequence Analysis and Prediction of Secondary Structure

The genetic sequences of $\mathrm{HN}-\mathrm{K}_{335}$ and $\mathrm{HN}-\mathrm{E}_{335}$ variants of Urabe AM9 mumps virus were determined [11], and the primary structures of their HN proteins were deduced. The amino acid sequences of three crystallized HN glycoproteins from Newcastle disease virus (NDV, accession: AF212323), human parainfluenza virus 3 (HuPIV-3, accession: AY283063) and simian parainfluenza virus 5 (SV5, accession: K02870) were obtained from GeneBank. HN amino acid sequences were aligned and compared with those of these paramyxoviruses, using ClustalW 1.8 (http://www.ebi.ac.uk/clustalw) [14]. The secondary structure was predicted by algorithms included in the following programs: Antheprot (http://antheprotpbil.ibcp.fr) [15], Psi-Pred (http://bioinf.cs.ucl.ac.uk/psipred/ psiform.html) [16], J-Pred (http://www.compbio.dundee.ac.uk/ $\sim$ www-jpred/submit.html) [17] and Prof(http://www.aber.ac.uk/ $\sim$ phiwww/prof) [18], and a secondary-structure-based alignment was obtained with ESPript 2.2 software (http:// espript.ibcp.fr/ESPript/cgi-bin/ESPript.cgi) [19].

\section{Construction and Analysis of Theoretical 3D Models}

The putative 3D structures and their homodimeric arrangements were obtained using the Swiss-Model Server (http://swissmodel.expasy.org) [20]. The quality of predicted structures was verified with the program WhatChek [21], also provided by the Swiss-Model Server. The molecular surface models of proteins were calculated with DeepView 3.7 and the electrostatic potentials fitted to their surfaces (http:// ca.expasy.org/spdbv) [22]. Electrostatic potentials were calculated with partial atomic charges of the GROMOS 43A1 force field and with dielectric constants of 4 and 80 for the protein and solvent, respectively, using the PoissonBoltzmann method and electric charge cut-off values of -1.8 $\mathrm{kT} / \mathrm{e}$ and $+1.8 \mathrm{kT} / \mathrm{e}$ for the negative and positive charges, respectively. Molecular surface models were built, assuming a solvent radius of $1.4 \AA$. We used Site Finder of MOE 2006.08 for the prediction of putative active sites in the mumps virus model [23]. The algorithm skips shallow surface grooves and concentrates on deeper and more surrounded locations in the protein matrix that have tight atomic packing. Final structural representations were obtained using the programs DeepView and MOE.

\section{Results and Discussion}

Studies on Cellular Membrane Receptors for $\mathrm{HN}_{-} \mathrm{K}_{335}$ and HN$\mathrm{E}_{335}$ Virus Variants

We previously demonstrated that the $\mathrm{HN}-\mathrm{K}_{335}$ variant of Urabe AM9 vaccine is efficiently replicated in human neuroblastoma cells, whereas the $\mathrm{HN}-\mathrm{E}_{335}$ virus variant is replicated significantly less [11]. We made further studies and found that sialic acid is an important component of cell receptors for $\mathrm{MuV}$, since viral infection was completely avoided by treatment of Vero and SH-SY5Y cells with $C$. perfringens neuraminidase before inoculation. However, these two variants differed in their sialic acid binding activity [13]. Table 1 shows the results of several assays of hemagglutinin-neuraminidase; the $\mathrm{HN}-\mathrm{K}_{335}$ and $\mathrm{HN}-\mathrm{E}_{335}$ variants of Urabe AM9 were found to have different biological activities.

Since several cell membrane glycoconjugates have terminal $\alpha 2,3-, \alpha 2,8$ - or $\alpha 2,6$-linked sialic acid residues, we performed antiviral assays using sialylated and non-sialylated molecules as competitive inhibitors. We found that both virus variants interacted with all the sialylated molecules; however, the HN$\mathrm{K}_{335}$ variant had higher affinity towards $\alpha 2,6$-linked sialic acid residues, whereas the $\mathrm{HN}-\mathrm{E}_{335}$ variant preferred $\alpha 2,3$-linked 
sialic acids [13]. This makes sense, given the higher neurotropism of the $\mathrm{HN}-\mathrm{K}_{335}$ virus [11] and the abundance of $\alpha 2,6$-linked sialic acid found on human nerve cells [13].

We performed other inhibition assays and observed that $\mathrm{HN}-\mathrm{K}_{335}$ possesses a higher affinity towards $\alpha 2,8$-linked sialic acids (colominic acid), which was evidenced by competence with colominic acid (Figure 1). $\mathrm{IC}_{50}$ values were $35.3 \pm 4.2$ and $80.7 \pm 6.5$ for $\mathrm{HN}-\mathrm{K}_{335}$ and $\mathrm{HN}-\mathrm{E}_{335}$, respectively. Along with higher expression of $\alpha 2,6$-linked sialic acids, it is well known that neuroblastoma cell membranes express $\alpha 2,8$-linked sialic acid [23], which would be advantageous for $\mathrm{HN}-\mathrm{K}_{335}$ replication.

We used hemadsorption assays to investigate the direct interaction of viruses with sialic acids. MuV-variant infected cells were incubated with human $\mathrm{O}$ red blood cells (RBC); both types of infected cells presented hemadsorption. Treatment of human $\mathrm{RBC}$ with C. perfringens neuraminidase completely eliminated their adsorption to cells infected with $\mathrm{HN}-\mathrm{K}_{335}$ or $\mathrm{HN}-\mathrm{E}_{335}$ virus variants (data not shown). This demonstrates that hemadsorption is mediated by sialic acid, which is recognized by both variants of Urabe AM9 mumps virus. These data are similar to what was found in previous assays, which showed that viral infection of both $\mathrm{MuV}$ variants is avoided by treatment of cells with $C$. perfringens neuraminidase [13].

In order to determine the role of membrane proteins in virus infection, we treated neuroblatoma cells with trypsin for 10 minutes. Increasing trypsin concentration enhanced virus infectivity (Figure 1). Since trypsin is a broad-range protease, it appears that cell membrane proteins play only a minor role in $\mathrm{MuV}$ entry into cells and that trypsin action favors infection by uncovering membrane glycolipids, as has been demonstrated in studies of in vitro infection with Sendai virus [25] and porcine rubulavirus LPMV [26].

We found that $\mathrm{HN}-\mathrm{K}_{335}$ virus neuraminidase preferably hydrolyzed $\alpha 2,3$-linked sialic acids; it had 11 times more activity than the HN-E ${ }_{335}$ neuraminidase (Table 1). There seems to be a conflict between the sialic acid specificities of $\mathrm{HN}-\mathrm{K}_{335}$ virus to perform either binding or hydrolysis; the former is directed towards $\alpha 2,6$ - and the latter against $\alpha 2,3$-linked sialic acids. We found that $\mathrm{HN}-\mathrm{K}_{335}$ virus binds both $\alpha 2,6$ - and $\alpha 2,3$-linked sialic acids; however, only $\alpha 2,6$-linked sialic acids are extensively expressed in the human central nervous system. The finding of $\alpha 2,3$-linked sialic acids in tissues of nonnervous origin led us to the notion that an $\alpha 2,3$-specific neuraminidase might play a role in reducing unproductive virus-cell interactions.

Similarity of Mumps Virus and Other ParamyxoViral HN Proteins

Our findings enabled us to conduct a structural analysis of the underlying events in order to gain more insight for a theoretical level of discussion.

In order to explore how $\mathrm{E} / \mathrm{K}_{335}$ substitution affected the $\mathrm{HN}$ glycoprotein conformation, the secondary, tertiary structures and other physicochemical properties were predicted for both $\mathrm{HN}-\mathrm{E}_{335}$ and $\mathrm{HN}-\mathrm{K}_{335}$ proteins.

Alignment of total protein sequences showed that Urabe AM9 mumps virus HN possesses the highest identity to SV5 (44\%), another member of the Rubulavirus genus, whereas NDV and HuPIV-3 HNs (belonging to Avulavirus and Respirovirus genera, respectively) has less identity with the total sequence of MuV HN ( $31 \%$ and 22\%, respectively). This led us to use the SV5 HN protein for comparison to carry out the structure prediction of $\mathrm{MuV} \mathrm{HN}$ variants. The total length of the SV $5 \mathrm{HN}$ protein (template) is 565 amino acids, but only 448 residues were visible in the 3D structure. Therefore our $\mathrm{MuV} \mathrm{HN}$ (target) 3D model contains the equivalent number of residues (positions 145-581 in Figure 2). The sequence identity between the target $\mathrm{MuV}$ protein (aa 145 to 581) and the template was $50 \%$, somewhat higher than that for the total sequence $(44 \%)$.

The secondary structure of MuV HN predicted with the Swiss-Model tools was used to perform a structure-based sequence alignment with other paramyxoviral $\mathrm{HN}$ proteins (Figure 2). Residue $335(\mathrm{~K} / \mathrm{E})$ of MuV HN was located at the third $\alpha$-helix $(\alpha 3)$, which seems to be conserved in the secondary structure but not in the amino acid sequence of SV5 and NDV.

The secondary structure of the $\mathrm{HN}$ proteins of MuV variants was also predicted using the algorithms Garnier, Gibrat, Levin, DPM and Predator (included in the Antheprot suite), as well as Psi-Pred, J-Pred and Prof. The consensus of these algorithms confirmed that $\mathrm{MuV} \mathrm{HN}$ possesses a rich -sheet structure, and that either $\mathrm{K}_{335}$ or $\mathrm{E}_{335}$ is located in a short $\alpha$-helix.

We concluded that HN serves as a multifunctional viral surface glycoprotein (Tables 1 and 2). We analyzed the amino acid sequences of both $\mathrm{HN}-\mathrm{K}_{335}$ and $\mathrm{HN}-\mathrm{E}_{335}$ virus variants, searching for residues involved in their biological activities. All critical amino acids involved in the neuraminidase active site of the crystallized proteins of SV5, NDV and HuPIV-3 were found in both $\mathrm{MuV}$ variants, demonstrating the importance of this enzymatic activity for paramyxoviruses (Table 2). In addition to its neuraminidase activity, this site has been recognized as the major receptor binding (hemagglutinating, hemadsorbing) domain, suggesting that $\mathrm{MuV} \mathrm{HN}$ protein uses the same site for both activities [2729]. Experimental point mutations made at several sites of NDV HN protein have shown that residues equivalent to E407, R422 and Y540 of MuV HN are directly involved in receptor binding [30].

A second sialic-acid-binding domain was recently found in NDV HN; it is located at the homodimer interface and involves several residues, the most important being G169 and R516 [31]. Those residues are replaced by P175 and P530 in $\mathrm{MuV} \mathrm{HN}$ protein. Due to physicochemical differences between these amino acids, it is improbable that the second domain is functional in $\mathrm{MuV}$, as in is the case for the SV5 HN protein, which also possesses $\mathrm{P}$ at equivalent residues and does not have the second sialic acid-binding site [29]. 
Table 1. Biological properties of Urabe AM9 mumps virus variants.

\begin{tabular}{|c|c|c|}
\hline Biological activity & HN-E ${ }_{335}$ & HN-K \\
\hline Replication titer in human nerve cells $(\mathrm{PFU})^{1}$ & $10^{4.50}$ & $10^{5.70}$ \\
\hline Replication titer in newborn rat brain $(\mathrm{PFU})^{2}$ & $10^{2.56}$ & $10^{3.58}$ \\
\hline Lysis of human nerve cells ${ }^{3}$ & $20-30 \%$ & $60-65 \%$ \\
\hline \multicolumn{3}{|c|}{ Infectivity inhibition of sialylated compounds $\left(\mathrm{IC}_{50}[\mu \mathrm{M}]\right)^{4}$} \\
\hline Sialyl $\alpha 2,3$ lactose & 19.5 & 48.0 \\
\hline Sialyl $\alpha 2,6$ lactose & 56.2 & 19.1 \\
\hline$\alpha 2,8$-linked polysialic acid ${ }^{5}$ & 80.7 & 35.3 \\
\hline \multicolumn{3}{|l|}{ Neuraminidase $\left(\mathrm{nmol} \mathrm{min}-1 \mathrm{mg}^{-1}\right)^{6}$} \\
\hline Sialyl $\alpha 2,3$ lactose & 1.90 & 11.24 \\
\hline Sialyl $\alpha 2,6$ lactose & 1.54 & 4.38 \\
\hline$\alpha 2,8$-linked polysialic acid & 1.38 & 3.65 \\
\hline \multicolumn{3}{|l|}{ Kinetics values ${ }^{7}$} \\
\hline $\mathrm{Km}(\mathrm{mM})$ & 0.70 & 0.65 \\
\hline $\operatorname{Vmax}\left(\mathrm{nmol} \min ^{-1} \mathrm{mg}^{-1}\right)$ & 3.50 & 37.50 \\
\hline Isoelectric point $(\mathrm{pI})^{8}$ & 4.65 & 4.30 \\
\hline
\end{tabular}

$\mathrm{PFU}=$ plaque forming units. ${ }^{1}$ Human neuroblastoma SH-SY5Y cells were inoculated with $0.02 \mathrm{PFU} /$ cell of $\mathrm{HN}-\mathrm{E}_{335}$ or $\mathrm{HN}-\mathrm{K}_{335}$ variants; replication titers were determined at $48 \mathrm{~h}$ post infection; ${ }^{2}$ one-old day rats were inoculated with $200 \mathrm{PFU}$ of $\mathrm{HN}-\mathrm{E}_{335}$ or $\mathrm{HN}-\mathrm{K}_{335}$ variants; brains were extracted and viral titers were determined at 4 days postinoculation; ${ }^{3} \mathrm{SH}-\mathrm{SY} 5 \mathrm{Y}$ cells were inoculated with $0.02 \mathrm{PFU} /$ cell of $\mathrm{HN}-\mathrm{E}_{335}$ or $\mathrm{HN}-\mathrm{K}_{335}$ variants; ${ }^{4}$ the $50 \%$ inhibitory concentration $\left(\mathrm{IC}_{50}\right)$ required to avoid viral infection of Vero cells was determined for each syalilated molecule, the lowest $\mathrm{IC}_{50}$ represent the highest virus sialic acid-binding affinity, and vice versa; ${ }^{5} \mathrm{IC}_{50}$ is reported as $\mathrm{mg} / \mathrm{mL} ;{ }^{6}$ neuraminidase activity was quantified by the thiobarbituric acid method, which determines the concentration of sialic acid released from mentioned substrates; ${ }^{7}$ kinetic values were determined using sialyl $\alpha 2,3$ lactose as substrate; ${ }^{8} \mathrm{pI}$ was determined by means of liquid electrophoresis using a $4-10 \mathrm{pH}$ gradient. The table was constructed with data from Santos-López et al., 2006 [1-3], Reyes-Leyva et al., 2007 [4,6,7], the present work [5], and unpublished results [8].

Table 2. Functional amino acids of MuV hemagglutinin-neuraminidase.

\begin{tabular}{lcccc}
\hline Activity & MuV & SV5 & NDV & PIV-3 \\
\hline Major receptor binding site & M 226 & F 209 & F 220 & D 238 \\
& K 228 & R 211 & S 222 & N 240 \\
& L 230 & L 213 & L 224 & R 242 \\
& E 407 & E 390 & E 401 & E 421 \\
& R 422 & R 405 & R 416 & R 436 \\
& Y 540 & Y 523 & Y 526 & Y 554 \\
Second receptor binding site & & & & \\
& P 162 & P 144 & F 156 & L 174 \\
& P 175 & P 158 & G 169 & V 187 \\
& P 530 & Q 513 & R 516 & A 544 \\
& Y 531 & F 514 & V 517 & I 545 \\
& N 533 & S 516 & S 519 & N 547 \\
& I 566 & L 549 & L 552 & S 580 \\
& V 567 & L 550 & F 553 & L 581 \\
& V575 & F 558 & L 561 & F 589 \\
& & & & \\
Neuraminidase & R 180 & R 163 & R 174 & R 192 \\
& D 204 & D 187 & D 198 & D 216 \\
& E 407 & E 390 & E 401 & E 409 \\
& R 422 & R 405 & R 416 & R 424 \\
& R 512 & R 495 & R 498 & R 503 \\
& Y 540 & Y 523 & Y 526 & Y 530 \\
& E 561 & E 544 & E 547 & E 549 \\
\hline & & & & \\
& & & & \\
& & & & \\
& & & &
\end{tabular}


Table 2. Functional amino acids of MuV hemagglutinin-neuraminidase (continuation).

\begin{tabular}{|c|c|c|c|c|}
\hline \multicolumn{5}{|l|}{ Fusion promoting } \\
\hline & S 222 & A 205 & Т 216 & D 234 \\
\hline & M 226 & F 209 & F 220 & D 238 \\
\hline & K 228 & $\mathrm{R} 211$ & $\mathrm{~S} 222$ & N 240 \\
\hline & L 230 & L 213 & L 224 & R 242 \\
\hline & V 567 & L 550 & F 553 & L 581 \\
\hline & Q 571 & Q 554 & R557 & Q 585 \\
\hline \multicolumn{5}{|l|}{$\mathrm{Ca}^{+2}$ binding } \\
\hline & D 268 & D 250 & D 261 & D 279 \\
\hline & $\mathrm{G} 270$ & S 253 & S 264 & S 282 \\
\hline & $\mathrm{S} 272$ & A 255 & V 266 & G284 \\
\hline & A 302 & A 285 & V 296 & A 316 \\
\hline
\end{tabular}

The first column presents the function associated with each set of residues. The following entries present the HN amino acid residues (single letter code and position) of both variants of mumps virus (MuV), simian virus 5 (SV5), Newcastle disease virus (NDV) and human parainfluenza virus 3 (PIV-3). Rows show the residues in equivalent positions. Conserved residues are in bold type. Data from references: [11,27,28,30-32,44-47].

Other important residues in $\mathrm{HN}$ include the heptad repeats at the membrane proximal domain. This region comprises approximately 90 amino acids and is rich in leucine and isoleucine. The key amino acids (I82, V89, V96, I104, L111 and $\mathrm{L118}$ ) in the MuV sequence are involved in the interaction of $\mathrm{HN}$ with fusion protein as well as in the promotion of cell membrane fusion in other paramyxoviruses, such as NDV, HuPIV-3 and Sendai virus [32,33]; although this region is not observed in the 3D-models. Moreover, all seven cysteines involved in disulfide linkages of template SV5 are conserved in the MuV target model (Figure 2). The second disulfide bond is not present in the NDV HN, while the second and fourth disulfide bonds are not present in HuPIV-3. This finding strengthens the likelihood of correct alignment and 3D modeling.

Predicted 3D Structure of $\mathrm{HN}-\mathrm{A}_{335}$ and $\mathrm{HN}-\mathrm{G}_{335}$ Proteins

The putative three-dimensional structure of the monomeric $\mathrm{HN}-\mathrm{K}_{335}$ and $\mathrm{HN}-\mathrm{E}_{335} \mathrm{MuV}$ variants were constructed with the SwissProt Server. Substantially similar 3D-models were obtained with Geno3D (http://geno3d-pbil.ibcp.fr/cgi-bin/ geno3d_automat.pl?page) [34] and Phyre (http:// www.sbg.bio.ic.ac.uk/ phyre); consequently, only the 3Dstructure predicted with the Swiss-Model is presented.

Both target structures are almost identical and presented the classic $\beta$-propeller neuraminidase motif [27]. This fold consists of a symmetrical structure, based on six twisted antiparallel $\beta$-sheets organized as a super barrel, with the active site at the central region. The head globular domain is formed by residues $145-581$ of the MuV HN protein. The stalk region (residues 1-144) of MuV HN was not modeled because the equivalent amino acids were not visible in the electron density maps of crystallized SV5 HN protein [29]. There was no apparent conformational change due to the presence of $\mathrm{K}$ or E in the amino acid 335 of HN protein, except for the R-chain, which is distinctly oriented for each amino acid (Figures 3A and $3 \mathrm{~B})$.
Superposition of the predicted HN protein structure of $\mathrm{MuV}$ variants over the crystallized HN protein structure of SV5, including the neuraminidase inhibitor DANA $(2,3-$ dehydro-2-deoxy-N-sialic acid or 2-deoxy-2,3-dehydro-nacetyl-neuraminic acid), permitted the localization of 10 amino acids (R180, D204, E264, Y268, Y303, E407, R422, R512, Y540, E551) that constitute the neuraminidase active site and directly interact with sialic acid. They were exactly the same in the two MuV HN variants (Table 2). The calculated geometrical deviation for the backbone and side chains of these 10 residues constitutes a minor irrelevant change of $0.26 \AA$, since the entire backbone formed by 448 $\mathrm{C}$-alpha atoms yields the same score (calculated as root mean squared distance).

The structural conformation of the active site was identical for the two $\mathrm{MuV}$ variants (Figure 3C), implying that at least at this level the corresponding proteins conserve their enzymatic activity. Nevertheless, the neuraminidase activity of $\mathrm{HN}-\mathrm{K}_{335}$ virus was higher than that of $\mathrm{HN}-\mathrm{E}_{335}$ (Table 1) [13]. This is difficult to explain, given the apparent conserved structure of the active sites.

Electrostatic Potential Analysis of $\mathrm{HN}_{3}-\mathrm{K}_{35}$ and $\mathrm{HN}-\mathrm{E}_{335} \mathrm{MuV}$ Proteins

Since evident structural differences that explain the changes in activity were not observed, we decided to investigate the electrostatic characteristics of each $\mathrm{HN}$ protein. As $\mathrm{K}$ and $\mathrm{E}$ residues are positively and negativelycharged amino acids, respectively, their opposite charges likely affect the isoelectric point (pI) of the protein. Indeed, their predicted pI differed significantly: 7.79 for $\mathrm{HN}-\mathrm{K}_{335}$ versus 6.99 for $\mathrm{HN}-\mathrm{E}_{335}$. However, we found that purified $\mathrm{HN}-\mathrm{K}_{335}$ and $\mathrm{HN}-\mathrm{E}_{335}$ proteins presented pIs of 4.30 and 4.65 , respectively (data not shown), similar to porcine rubulavirus $\mathrm{HN}$ protein ( $\mathrm{pI}$ 4.4) and other neuraminidases [35]. This difference between theoretical and experimental values could be because predicted $\mathrm{pI}$ is only based on 
Figure 1. Effect of trypsin and colominic acid on viral infectivity of MuV variants. SH-SY5Y cells were treated with different concentrations of pancreatic bovine trypsin (A) prior to infection with either $\mathrm{HN}-\mathrm{K}_{335}$ or $\mathrm{HN}-\mathrm{E}_{335}$ variants. The inhibitory effect of colominic acid (B) was determined by incubation of $\mathrm{MuV}$ variants with different concentrations of this molecule for $1 \mathrm{~h}$ at $4^{\circ} \mathrm{C}$. Infection was done at an MOI of 0.02 , and inhibition titers were determined by plaque forming assays.
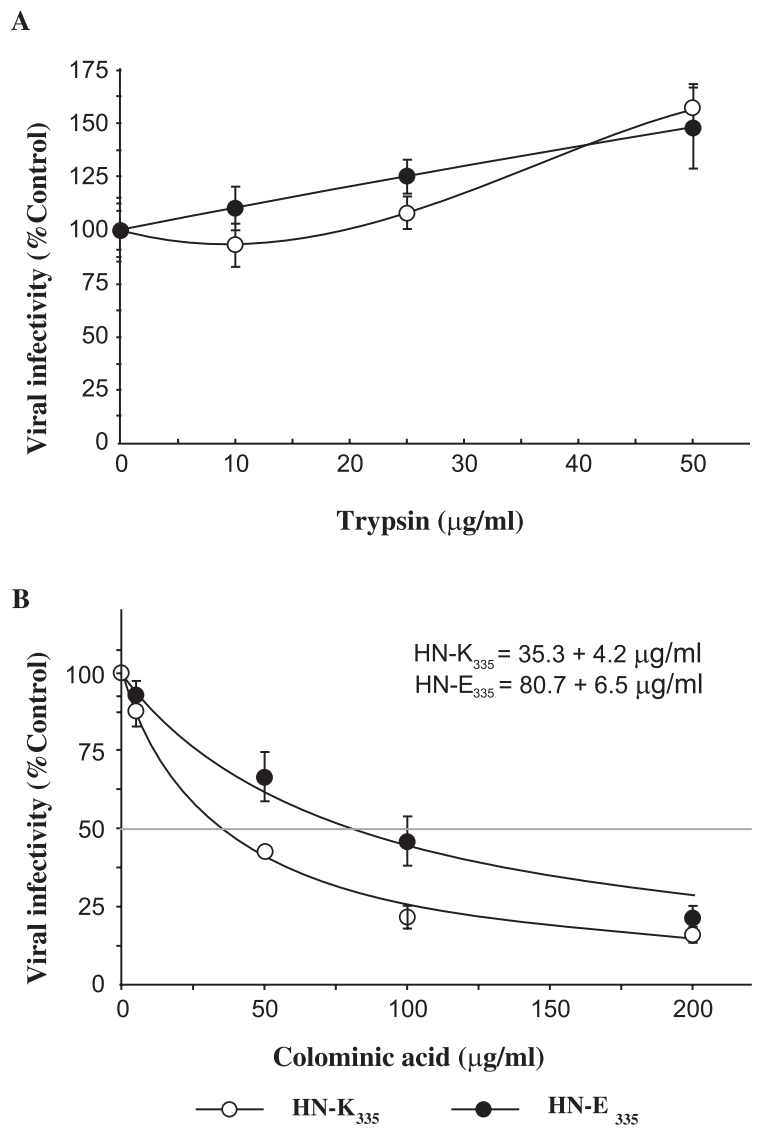

amino acid sequences, although it can be modified in nature by glycosylation, as has been demonstrated for other viral glycoproteins $[35,36]$. Since, both $\mathrm{HN}-\mathrm{K}_{335}$ and $\mathrm{HN}-\mathrm{E}_{335}$ proteins preserved the seven potential N-glycosylation sites (Figure 2), it is probable that as for other $\mathrm{MuV}$ strains, at least five are actually occupied by carbohydrate sidechains that reduce the $\mathrm{pI}$ values $[37,38]$.

An electrostatic potential map showed a drastic change at the $\alpha 3$ helix, with positive charges loaded on $\mathrm{HN}-\mathrm{K}_{335}$ and negative charges loaded on $\mathrm{HN}-\mathrm{E}_{335}$ protein (Figure $3 \mathrm{D}-\mathrm{G})$. This amino acid substitution $(\mathrm{K} / \mathrm{E})$ appears to affect the surrounding residues, either increasing or decreasing the electrostatic potential of the neighboring $\beta$-sheet motifs. Surface representations of the electrostatic potential clearly showed that monomers of $\mathrm{HN}-\mathrm{K}_{335}$ and $\mathrm{HN}-\mathrm{E}_{335}$ proteins are quite different, but their differences increase with dimerization; consequently, $\mathrm{HN}-\mathrm{E}_{335}$ seems to be highly negative, while $\mathrm{HN}-\mathrm{K}$ dimers possess positive to neutral potential that reaches the upper side of the catalytic domain (Figures 3F and 3G). Attraction and repulsion forces are important factors in the approaching and selective attachment of proteins and other biological macromolecules, and therefore they affect their functionality [39]. More importantly, the electrostatic potential shown by each HN protein could affect its interaction with substrates, cell receptors or other viral proteins.

Sialic acids constitute part of the cell receptors for paramyxoviruses. Their negative charge at physiological $\mathrm{pH}$ is due to the carboxyl group and is important for specific interactions with viral or cellular ligands [40]. Sialic acids are located at the terminal position of many glycoproteins and glycolipids on cell membranes. As some of those molecules are rich in sialic acids, their electrostatic potential can be highly negative, avoiding contacts with some molecules, while permitting some specific interactions, such as that with $\mathrm{HN}$ protein. This fact may be very important for colominic acid, because this molecule includes various successive Neu5Ac residues and its negative charge is high. The specific interaction of the carboxyl group of DANA (a sialic acid analogue) and the arginine triad (R180, R422 and R512) is conserved in all paramyxovirus $\mathrm{HN}$ proteins (Figure $3 \mathrm{C}$ ).

The precise role of the $\alpha 3$ helix is unknown; it constitutes part of a structurally variable region that also includes the $\alpha 4$ helix, the N-terminal region and the loops 452 (424 in SV5) and 493 (476 in SV5), since HuPIV-3, NDV and SV5 HN proteins differ considerably in the spatial distribution of these domains. The high variability and location of N-linked glycosylation sites at this region suggest that it results in individual characteristics of each HN protein and may account for their differences in cell receptor specificity and cooperation with homologous F protein [29]. Additionally, the exposed localization of $\alpha 3$ helix on the HN protein surface suggests that it has an immunogenic role. Evidence of this comes from a report that variants bearing $\mathrm{E}_{335}$ were completely neutralized in vitro, whereas variants containing $\mathrm{K}_{335}$ escaped neutralization [9].

Putative Dimeric Structure of $\mathrm{HN}-\mathrm{K}_{335}$ and $\mathrm{HN}-\mathrm{E}_{335}$ Proteins

The 3D-models of dimeric structures of $\mathrm{MuV} \mathrm{HN}$ proteins are depicted in Figures 4A and 4B. These structures are similar to other known HNs, such as NDV and PIV3 dimers. The amino acid $\mathrm{E} / \mathrm{K}_{335}$ is located at opposite positions of the dimerization site: residues 226 to 237 (MFKTLKIQYLSD in Figure 4C), which explains why the formation of the dimeric structure is not affected by this amino acid change, and it means that $\mathrm{HN}-\mathrm{K}_{335}$ and $\mathrm{HN}-\mathrm{E}_{335}$ proteins probably present dimeric forms, as has been observed in other paramyxoviruses [41]. In a previous study, we observed that enzymatic kinetics of two $\mathrm{MuV}$ variants presented a cooperative curve, typical of allosteric enzymes, and an oligomerization factor of 2, which suggests that the active enzyme is a dimeric form [13]. 
Figure 2. Structure-based sequence alignment of MuV HN (first line in alignment block) with possible 3D structure templates for the target segment. To date, only three paramyxoviral HN proteins (following three block lines) have been crystallized and can be used as templates. SV5 in the second line corresponds to the structure (PDB code: 1Z50) used for target modeling. Both target sequences $\left(\mathrm{HN}-\mathrm{K}_{335}\right.$ and $\mathrm{HN}-\mathrm{E}_{335}$ ) are presented in the first line, differing only in residue 335 by lysine or glutamic acid, labeled with symbol $\mathrm{X}$ and marked by the vertical arrow. The numbers and secondary structure above the alignment correspond to MuV $\mathrm{HNs}$, which were taken from the SwissModel prediction. Arrows and spirals represent the $\beta$-sheet and $\alpha$-helix motifs of MuV HN. Boxes show similarities. Letters enclosed in filled black boxes represent amino acid identity. Black triangles indicate glycosylation sites, and grey numbers mark cysteines that form disulfide bonds. The nomenclature $\beta \mathrm{iSj}$ corresponds to the jth strand in the ith $\beta$-sheet. Helices were named according to NDV and SV5 HN counterparts. The initial alignment was produced with ClustalW 1.8 and then treated with Espript 2.2.

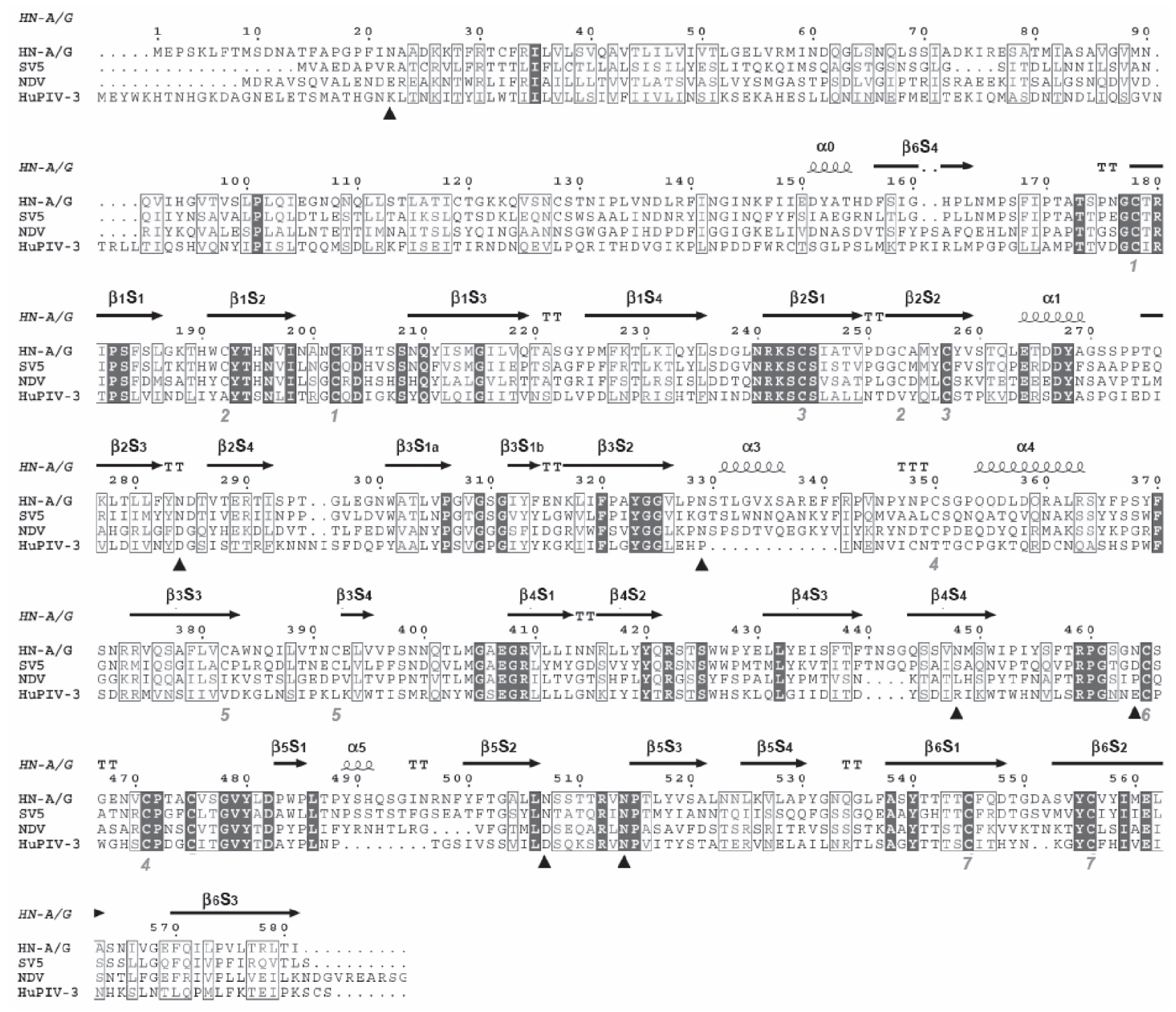

In Figure 4C, the small gray and red spheres reflect the non-polar and polar attraction in the contact zone of the dimer. The polar spots coincide with hydrogen bonding, while the non-polar zones involve Van der Waals attractions. The program finds active sites of sialic acid ligand (surrounded by red and gray spheres, top left and bottom right in Figure 4C). The dimer interface is also recognized as a water exclusion zone by favorable hydrophobic contacts and hydrogen bonding (diagonal top right to bottom left in Figure 4C. This in silico evidence could be validated by further physicochemical experiments, such as native and denaturing electrophoresis or Western blot assays in order to identify the putative protein isoforms.

The oligomerization process occurs in the endoplasmic reticulum, where $\mathrm{HN}$ is synthesized by associated ribosomes; this is also where the glycosylation process begins [41]. The 


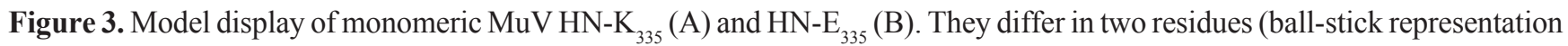
to the left) located in a small helical section of the surface: lysine colored in cyan (A) and glutamic acid in magenta(B). Yellow arrows represent $\beta$-sheet regions and green spirals represent a-helices $(\mathrm{A}, \mathrm{B})$. The HN proteins are visible in the top view (looking down the viral surface towards the inside) for both MuV variants (A, B). The active sites of $\mathrm{HN}-\mathrm{K}_{335}$ and $\mathrm{HN}-\mathrm{E}_{335}$ target proteins are depicted in superposition (C). Due to overlapping positions of the residues, the stick representation shows yellow $\left(\mathrm{HN}-\mathrm{K}_{335}\right)$ and cyan $\left(\mathrm{HN}-\mathrm{E}_{335}\right)$ contributions. The bound ligand (center) is a derivative of sialic acid (DANA, $\mathrm{C}$ white, $\mathrm{O}$ red, $\mathrm{N}$ blue, $\mathrm{H}$ omitted). The fragment containing the $\alpha 3$ region of $\mathrm{MuV}$ variant $\mathrm{HN}$ proteins is shown in (D) and (E), respectively. Modeling of molecular surface for MuV HN proteins ( $\mathrm{F}$ and $\mathrm{G}$ ); the ribbon structure corresponds to $\mathrm{HN}-\mathrm{K}_{335}$ or $\mathrm{HN}-\mathrm{E}_{335}$ proteins for which the molecular surface was calculated and presented according to negative (red) or positive (blue) electrostatic potential. The top $(\mathrm{F})$ and a side views $(\mathrm{G})$ are presented as a surface representation. The yellow arrow indicates the $\mathrm{K}_{335}$ or $\mathrm{E}_{335}$ residue. The atom partial charges were loaded from the GROMOS 43A1 force field using DeepView.
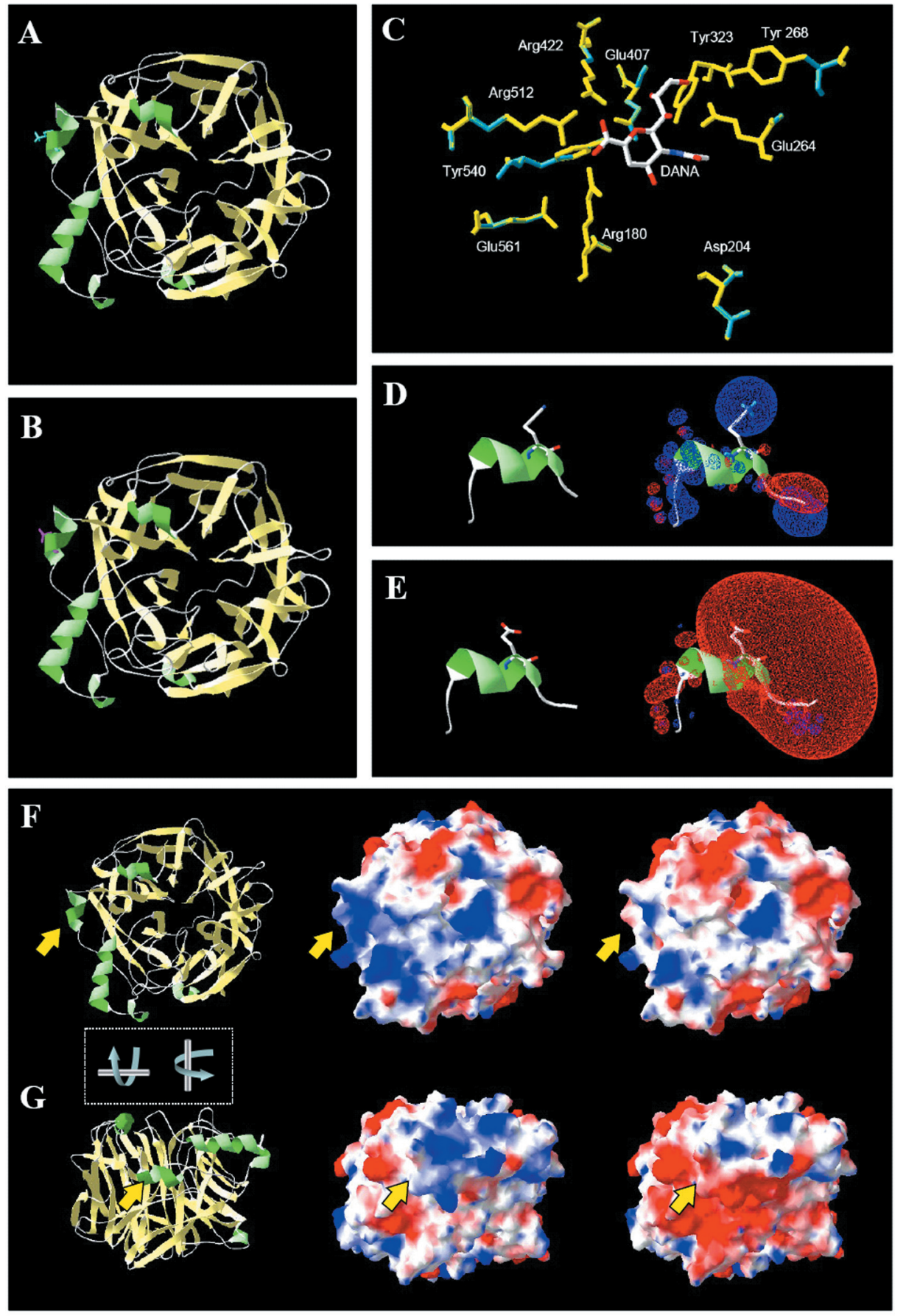
Figure 4. Displaying the dimeric models of both MuV HN target proteins. A and B present HN under different angles, top: ribbon display of the common backbone for both mutants; below: molecular surface representation for each $\mathrm{MuV}$ variant. The entrance of the active site is visible thanks to the docked neuraminidase inhibitor (DANA) in red (ribbon structure) or green (surface representation). The yellow arrow indicates the location of $\mathrm{K}_{335}$ and $\mathrm{E}_{335}$ residues in both mutants (dashed arrows indicates that residue 335 is located behind). The mutation causes a major shift in the electrostatic surface properties: more positively charged (blue) due to cationic lysine (center) and inversely, more negatively charged (red) due to glutamate anion (right). The remainder (white) marks the zero - electrostatic potential. (C) Display of the homodimer interface, which is identical for both MuV HN target proteins. Their backbones are colored in blue or green. Stick representation of the residues in the interface zone (all H atoms omitted except essential ones). Hydrogen bonds are dotted by yellow lines, Van der Waals attractions are marked by dotted lines in magenta. Each monomer contains a docked sialic acid ligand in space fill display colored by atom types (grey $\mathrm{C}$, red $\mathrm{O}$, blue $\mathrm{N})$. The small gray and red spheres symbolize hydrophobic and polar attraction, respectively. The calculations and final presentation were developed with DeepView (A and B) or MOE (C).
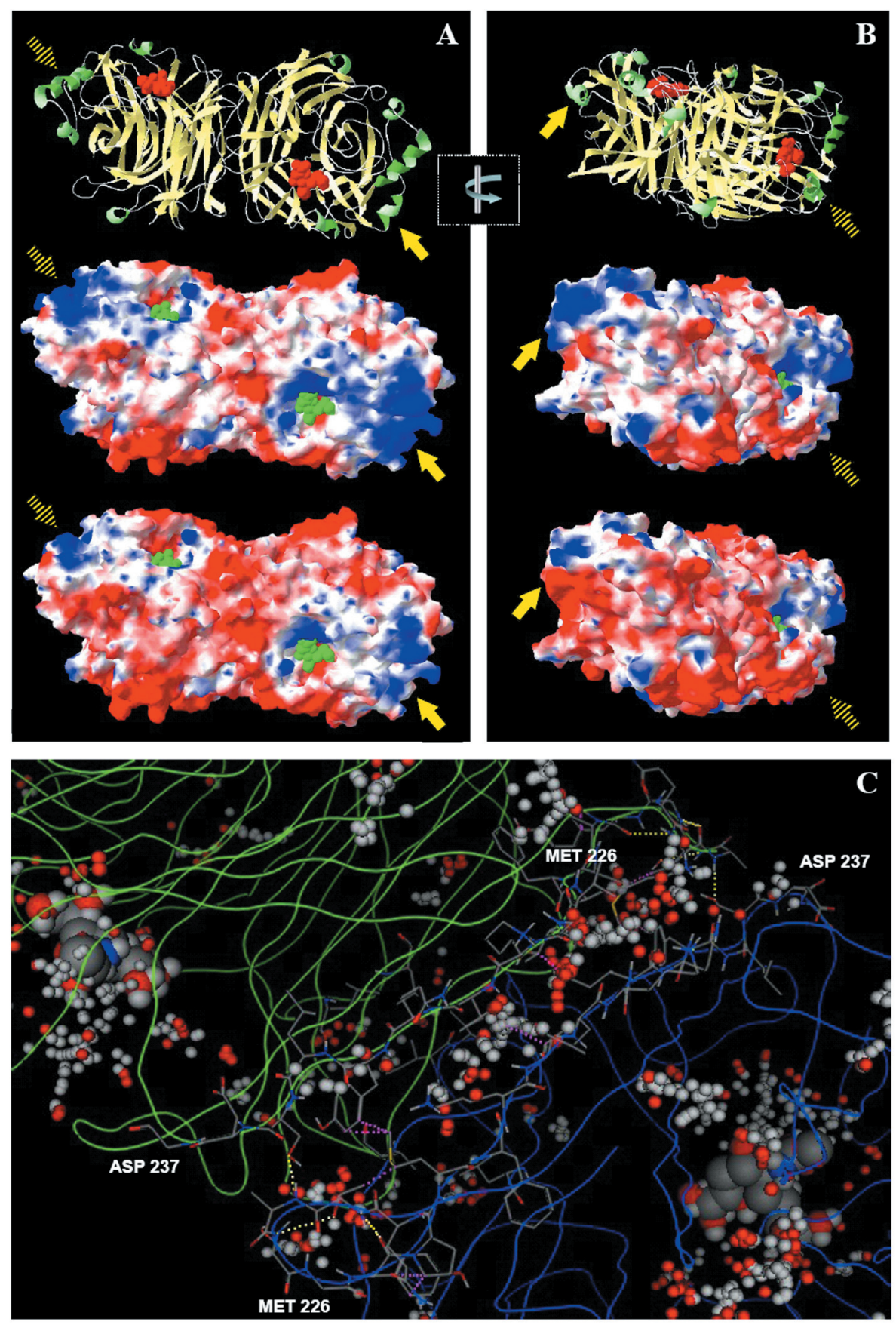
oligomerization or folding of a protein can be affected by factors such as $\mathrm{pH}$ and redox potential. The $\alpha 3$ domain is close to a glycosylation site sequence NSTL between residues 329-332 and is spanned only by two amino acids of the $\mathrm{E}$ or $\mathrm{K}$ residue. It is not known if this electrostatic change exerts an influence on glycosylation, folding or oligomerization, because these processes are all related in space and time during protein sorting, which can be another differentiating feature between $\mathrm{HN}$ proteins. Recently, similar in silico methods, including homology modeling, surface and functional analysis of 3D models to map antigenic sites, were successfully used on different variants of mumps virus to analyze the influence of variability in strains and antigenic sites of mumps viruses [42]. More details about membrane fusion and virus cell interactions can be found in a comprehensive review by Lamb et al. [43].

\section{Concluding Remarks}

Although no structural differences were found between HN proteins, their electrostatic potentials were notably affected by the change at amino acid 335 . The $\mathrm{HN}-\mathrm{K}_{335}$ protein possesses a more equilibrated electrostatic potential, whereas $\mathrm{HN}-\mathrm{E}_{335}$ is predominantly negative. This would explain the different interactions of $\mathrm{HN}$ protein with sialic acids used as cell receptors. Experimental evidence suggests that these electrostatic differences are a factor in the high activity of HN-A ${ }_{1081}$ virus neuraminidase. Nevertheless, further experimental assays to identify the participation of $\mathrm{HN}$ protein on $\mathrm{MuV}$ neurovirulence are needed.

\section{Acknowledgments}

This work was supported by grants from Consejo Nacional de Ciencia y Tecnología (CONACYT: 30625-M, Salud-2003C01-085 and 52639/2007) and Fondo para el Fomento de la Investigación Médica, IMSS (FP-2002/119; FP 2003/028).

\section{References}

1. Geeta M.G., Kumar P.K. Mumps-need for urgent action. Indian Pediatr 2004;41:1181-2.

2. Vandermeulen C., Roelants M., Vermoere M., et al. Outbreak of mumps in a vaccinated child population: a question of vaccine failure? Vaccine 2004;22:2713-6.

3. Centers for Disease Control and Prevention (CDC). Mumps epidemic-Iowa, 2006. MMWR Morb. Mortal Wkly Rep 2006;55:366-8.

4. Galazka A.M., Robertson S.E., Kraigher A. Mumps and mumps vaccine: a global review. Bull. World Health Organ 1999;77:314.

5. Dourado I., Cunha S., Teixeira M.G., et al. Outbreak of aseptic meningitis associated with mass vaccination with a urabecontaining measles-mumps-rubella vaccine: implications for immunization programs. Am J Epidemiol 2000;151:524-30.

6. Atrasheuskaya A.V., Neverov A.A., Rubin S., Ignatyev G.M. Horizontal transmission of the Leningrad-3 live attenuated mumps vaccine virus. Vaccine 2006;24:1530-6.

7. Brown E.G., Dimock K., Wright K.E. The Urabe AM9 mumps vaccine is a mixture of viruses differing at amino acid 335 of the hemagglutinin-neuraminidase gene with one form associated with disease. J Infect Dis 1996;174:619-22.
8. Cusi M.G., Santini L., Bianchi S., et al. Nucleotide sequence at position 1081 of the hemagglutinin-neuraminidasegene in wildtype strains of mumps virus is the most relevant marker of virulence. J Clin Microbiol 1998;36:3743-4.

9. Afzal M.A., Yates P.J., Minor P.D. Nucleotide sequence at position 1081 of the hemagglutinin-neuraminidase gene in the mumps Urabe vaccine strain. J Infect Dis 1998;177:265-6.

10. Amexis G., Fineschi N., Chumakov K. Correlation of genetic variability with safety of mumps vaccine Urabe AM9 strain. Virology 2001;287:234-41.

11. Santos-Lopez G., Cruz C., Pazos N., et al. Two clones obtained from Urabe AM9 mumps virus vaccine differ in their replicative efficiency in neuroblastoma cells. Microbes Infect 2006;8:332-9.

12. Lamb R.A., Kolakofsky D. Paramyxoviridae: the viruses and their replication. In: Knipe D.M., Howley P.M. eds. Fields Virology (4th ed.). Philadelphia: Lippincott, Williams \& Wilkins, 2001.

13. Reyes-Leyva J., Baños R., Borraz-Arguello M., et al. Amino acid change $335 \mathrm{E}$ to $\mathrm{K}$ affects the sialic-acid-binding and neuraminidase activities of Urabe AM9 mumps virus hemagglutininneuraminidase glycoprotein. Microbes Infect 2007;9:234-40.

14. Chenna R., Sugawara H., Koike T., et al. Multiple sequence alignment with the Clustal series of programs. Nucleic Acids Res 2003; $31: 3497-500$.

15. Deleage G., Combet C., Blanchet C., Geourjon C. ANTHEPROT: an integrated protein sequence analysis software with client/ server capabilities. Comput Biol Med 2001;31:259-67.

16. McGuffin L.J., Bryson K., Jones D.T. The PSIPRED protein structure prediction server. Bioinformatics 2000;16:404-5.

17. Cuff J.A., Clamp M.E., Siddiqui A.S., et al. JPred: a consensus secondary structure prediction server. Bioinformatics 1998; $14: 892-3$

18. Rost B., Yachdav G., Liu J. The PredictProtein server. Nucleic Acids Res 2004;32:W321-W326.

19. Gouet P., Robert X., Courcelle F. ESPript/ENDscript: extracting and rendering sequence and $3 \mathrm{D}$ information from atomic structures of proteins. Nucleic Acids Res 2003;31:3320-3.

20. Kopp J., Schwede T. The SWISS-MODEL repository of annotated three-dimensional protein structure homology models. Nucleic Acids Res 2004;32:D230-4.

21. Hooft R.W., Vriend G., Sander C., Abola E.E. Errors in protein structures. Nature 1996;381:272.

22. Guex N., Peitsch M.C. SWISS-MODEL and the Swiss-PdbViewer: An environment for comparative protein modeling. Electrophoresis 1997; 18:2714-23.

23. MOE (The Molecular Operating Environment), Version 2006.08, software, Chemical Computing Group Inc., 1010 Sherbrooke Street West, Suite 910, Montreal, Canada H3A 2R7. http:// www.chemcomp.com. 2007.

24. Glick M.C., Livingston B.D., Shaw G.W., et al. Expression of polysialic acid on human neuroblastoma. Prog Clin Biol Res 1991;366:267-74.

25. Markwell M.A., Fredman P., Svennerholm L. Specific gangliosides are receptors for Sendai virus. Proteins in lipid samples can mask positive biological effects. Adv Exp Med Biol 1984;74:369-79.

26. Reyes-Leyva J., Hernandez-Jauregui P., Montano L.F., Zenteno E. The porcine paramyxovirus LPM specifically recognizes sialyl(alpha 2,3)lactose-containing structures. Arch Virol 1993; $133: 195-200$.

27. Crennell S., Takimoto T., Portner A., Taylor G. Crystal structure of the multifunctional paramyxovirus hemagglutininneuraminidase. Nat Struct Biol 2000;7:1068-74.

28. Lawrence M.C., Borg N.A., Streltsov V.A., et al. Structure of the haemagglutinin-neuraminidase from human parainfluenza virus type III. J Mol Biol 2005;335:1343-57.

29. Yuan P., Thompson T.B., Wurzburg B.A., et al. Structural studies of the parainfluenza virus 5 hemagglutinin-neuraminidase tetramer in complex with its receptor, sialyllactose. Structure 2005; $13: 803-15$. 
30. Connaris H., Takimoto T., Russell R., et al. Probing the sialic acid binding site of the hemagglutinin-neuraminidase of Newcastle disease virus: identification of key amino acids involved in cell binding, catalysis, and fusion. J Virol 2002;76:1816-24.

31. Zaitsev V., von Itzstein M., Groves D., et al. Second sialic acid binding site in Newcastle disease virus hemagglutinin-neuraminidase: implications for fusion. J Virol 2004;78:3733-41.

32. Stone-Hulslander J., Morrison T.G. Mutational analysis of heptad repeats in the membrane-proximal region of Newcastle disease virus HN protein. J Virol 1999;73:3630-7.

33. Wang Z., Iorio R.M. Amino acid substitutions in a conserved region in the stalk of the Newcastle disease virus HN glycoprotein spike impair its neuraminidase activity in the globular domain. J Gen Virol 1999;80:749-53.

34. Combet C., Jambon M., Deleage G. Geourjon C. Geno3D: automatic comparative molecular modelling of protein. Bioinformatics 2002; $18: 213-4$.

35. Santos-López G., Flores E., Baños R., et al. Purification of Porcine rubulavirus attachment protein by isoelectric focusing. Prot Expr Purif 2004;35:120-5.

36. Luo C., Nobusawa E., Nakajima K. Analysis of the desialidation process of the haemagglutinin protein of influenza $\mathrm{B}$ virus: the host-dependent desialidation. J Gen Virol 2002;83:1729-34.

37. Herrler G., Compans R.W. Posttranslational modification and intracellular transport of mumps virus glycoproteins. J Virol 1983;47:354-62.

38. Waxham M.N., Aronowski J., Server A.C., et al. Sequence determination of the mumps virus HN gene. Virology 1988; $164: 318-25$.
39. Betts M.J., Sternberg M.J. An analysis of conformational changes on protein-protein association: implications for predictive docking. Protein Eng 1993;12:271-83.

40. Schauer R. Achievements and challenges of sialic acid research. Glycoconj J 2000;17:485-99.

41. Doms R.W., Lamb R.A., Rose J.K., Helenius A. Folding and assembly of viral membrane proteins. Virology 1993;193:545-62.

42. Kulkarni-Kale U., Ojha J., Manjari G.S., et al. Mapping antigenic diversity and strain specificity of mumps virus: a bioinformatics approach. Virology 2007;359:436-46.

43. Lamb R.A., Paterson R.G. Jardetzky T.S. Paramyxovirus membrane fusion: lessons from the $\mathrm{F}$ and $\mathrm{HN}$ atomic structures. Virology 2006;344:30-7.

44. Tsurudome M., Kawano M., Yuasa T., et al. Identification of regions on the hemagglutinin-neuraminidase protein of human parainfluenza virus type 2 important for promoting cell fusion. Virology 1995;213:190-203.

45. Bousse T., Takimoto T., Portner A. A single amino acid changes enhances the fusion promotion activity of human parainfluenza virus type 1 hemagglutinin-neuraminidase glycoprotein. Virology 1995;209:654-7.

46. Takimoto T., Taylor G.L., Connaris H.C., et al. Role of the hemagglutinin-neuraminidase protein in the mechanism of paramyxovirus-cell membrane fusion. J Virol 2002;76:13028-33.

47. Corey E.A., Mirza A.M., Levandowsky E., Iorio R.M. Fusion deficiency induced by mutations at the dimer interface in the Newcastle disease virus hemagglutinin-neuraminidase is due to a temperature-dependent defect in receptor binding. J Virol 2003;77:6913-22. 